\title{
Treatment of seawater immersion-complicated open-knee joint fracture
}

\author{
J.G. Ai ${ }^{1}$, F. Zhao ${ }^{1}$, Z.M. Gao ${ }^{2}$, W. Dai ${ }^{2}$, L. Zhang ${ }^{2}$, H.B. Chen ${ }^{2}$ and \\ J.G. Zhou ${ }^{2}$
}

${ }^{1}$ Department of Orthopaedics, The 180th Hospital of PLA, Quanzhou, China

${ }^{2}$ State Key Laboratory of Trauma, Burns and Combined Injury,

Department 4, Research Institute of Field Surgery, Daping Hospital, Third Military Medical University, Chongqing, China

Corresponding author: J.G. Ai

E-mail: jianguoaicn@163.com

Genet. Mol. Res. 13 (3): 5523-5533 (2014)

Received June 17, 2013

Accepted March 24, 2014

Published July 25, 2014

DOI http://dx.doi.org/10.4238/2014.July.25.6

\begin{abstract}
The current study aimed to select suitable remedies for seawater immersion-complicated open-knee joint fracture by exploring the effects of different treatment methods. Forty adult rabbits weighing $2.20 \pm 0.25 \mathrm{~kg}$ were divided equally into internal fracture fixation group (A), seawater-immersed group with primary internal fixation (B), seawater-immersed group with secondary internal fixation (C), and seawater-immersed group with external fixation (D), using the randomdigit table method. Open-femoral internal condylar fracture models were established. Group A was left untreated for $2 \mathrm{~h}$, whereas the other three groups were subjected to seawater immersion for $2 \mathrm{~h}$. Afterwards, groups A and B underwent debridement and steel plate and screw internal fixation. Group $\mathrm{C}$ underwent debridement and external fixation, which was followed by secondary steel plate and screw internal fixation after the wound healed. Group D underwent transarticular arthrodesis. Wound infection, joint functional rehabilitation, and radiological and histopathological changes in fracture healing in each group were assessed. The results showed that delayed internal fixation effectively
\end{abstract}


reduces the infection rate of seawater immersion-complicated open fracture and benefits joint function rehabilitation.

Key words: Seawater immersion injury; Knee joint; Open fracture; Fracture fixation; Rabbit

\section{INTRODUCTION}

Fracture complicated by seawater immersion is common in modern sea and landing battles as well as sea activities (Smith, 1995; Gerding, 2002; von Bertele, 2007). The traumatic characteristics and early treatment of seawater immersion-complicated open fracture have been preliminarily reported (Lin and Ruan, 2004; Yang et al., 2005). This condition has a high infection rate and a high malformation rate of calluses at the broken ends; for long bone fracture, external fixation effectively reduces the infection rate and enhances recovery (Xue et al., 2008). However, considering that many bone fractures are accompanied by intraarticular fracture or have broken ends located around the joint, transarticular external fixation is necessary to achieve effective fixation (Wang et al., 2007). As such a treatment brings about long-term inactivity of the joint, it may affect joint functional restoration (Stoquart et al., 2008; van der Krogt et al., 2010). What influence will the external fixator bring about to the joint during its use? Can delayed internal fixation reduce as much as possible the negative influence of transarticular fixation on articular functions as well as the infection and death rates from seawater immersion-complicated joint fracture? To solve these questions, we established rabbit open-knee joint fracture models and determined the effects of different fixation methods on wound infection, restoration of joint function, and fracture healing after open-knee joint fracture complicated by seawater immersion. The aim of this study was to provide a scientific and reference basis for method selection in the treatment of this condition.

\section{MATERIAL AND METHODS}

\section{Animals and grouping}

Forty adult rabbits of either sex weighing $2.20 \pm 0.25 \mathrm{~kg}$ were supplied by the Experimental Animal Center of the Research Institute of Surgery of Daping Hospital of the Third Military Medical University. The animals were randomized into four groups with 10 in each. They were subjected to open-knee joint fracture. Group A was the internal fracture fixation control group. The animals were left untreated for $2 \mathrm{~h}$ and internal fracture fixation was then performed. Group B constituted the seawater-immersed group with primary internal fixation. The animals were subjected to seawater immersion for $2 \mathrm{~h}$ immediately after fracture, and internal fracture fixation was then performed. Group $\mathrm{C}$ was the seawater-immersed group with secondary internal fixation. The animals were subjected to seawater immersion for $2 \mathrm{~h}$ immediately after open-knee joint fracture and then external splint fixation. After the wounds healed, they underwent fracture dissection and plate and screw internal fixation. Group D was the seawater-immersed group with external fixation. The animals were subjected to seawater immersion for $2 \mathrm{~h}$ immediately after open-knee joint fracture, and external fixation was then performed. 
This study was carried out in strict accordance with the recommendations in the Guide for the Care and Use of Laboratory Animals of the National Institutes of Health. The animal use protocol had been reviewed and approved by the Institutional Animal Care and Use Committee (IACUC) of the 180th Hospital of PLA.

\section{Model establishment}

After skin preparation, each animal was anesthetized via an ear marginal vein with $1.5 \%$ sodium pentobarbital at $1-2 \mathrm{~mL} / \mathrm{kg}$ (Guangdong Bangmin Pharmaceutical Co., Ltd., China). A 2.5-cm long incision was made on the medial side of the right knee joint. Muscles and ligaments were bluntly dissected to expose the knee joint and the inferior end of the femur. The animal was fixed supine on a stand. A self-made vertical impact machine with a $1.5 \times 1.2-$ $\mathrm{cm}$ inverse L-shaped impact knife edge was utilized. The weight dropper of the machine was lifted $50 \mathrm{~cm}$ high and then released for a free fall to collide with the knife holder. Models of femoral medial condyle amputation and open fracture were established.

Group A did not receive any treatment. The animals in groups B, C, and D were fixed on specially made rabbit frames, and then the frames were placed on plastic buckets $(20 \mathrm{~cm}$ in diameter and 25 in height) full of seawater to let the lower limbs of the animals be immersed. Seawater temperature was controlled between $20^{\circ}$ and $22^{\circ} \mathrm{C}$ using the water bath method. Seawater was taken from the Quanzhou sea area of the Taiwan Strait, and had the following key parameters: $26.518 \mathrm{~g} / \mathrm{L} \mathrm{NaCl} ; 22.447 \mathrm{~g} / \mathrm{L} \mathrm{MgCl} ; 3.305 \mathrm{~g} / \mathrm{L} \mathrm{MgSO}_{4} ; 1.141 \mathrm{~g} / \mathrm{L} \mathrm{CaCl}_{2}$; $0.725 \mathrm{~g} / \mathrm{L} \mathrm{KCl}$; and $1250-1350 \mathrm{mOsm} / \mathrm{L}$. All animals were subjected to debridement, fracture reduction, and fracture fixation after $2 \mathrm{~h}$.

\section{Fracture fixation and postoperative handling}

All animals were subjected to debridement and then fracture fixation. Degenerated skin, muscles, joint capsules, adipose capsules, and periostea were removed until blood oozing. The wound was washed with $0.45 \%$ hypotonic physiological saline and then soaked with povidone iodine for $5 \mathrm{~min}$. Groups A and B underwent internal fracture fixation with plates and drive screws (Jiangsu Kanghui, China). Primary closure was performed and aseptic dressings were regularly changed. Group $\mathrm{C}$ received cylinder cast external fixation. The wound was left open. Aseptic dressing and local windowing of the wound were performed. The dressing was changed regularly. After the wound healed, fracture dissection and plate and drive screw internal fixation were performed. Group D underwent transarticular external fixation, and the wound was left open. Aseptic dressing, local windowing of the wound, regular dressing changes, and secondary suture were performed.

After operation, the animals were caged separately. They were given $800,000 \mathrm{U}$ sodium benzylpenicillin (Northeast Pharmaceutical Group Shengyang No. 1 Pharmaceutical Co., Ltd., China), $5 \mathrm{~mL} \mathrm{0.5 \%} \mathrm{metronidazole} \mathrm{injection} \mathrm{(Binzhou} \mathrm{Pharmaceutical} \mathrm{Company,} \mathrm{China),}$ and $5 \mathrm{~mL} 0.2 \%$ levofloxacin lactate and sodium chloride injection (BBCA Pharmaceutical, China) by intravenous drip via the ear marginal vein twice per day for 5 successive days.

The dead animals within 7 days after operation were replaced. Redebridement, openwound dressing, and secondary suture were performed in animals with infection even 5 days after anti-infective treatment. Anti-infective treatment with effective antibiotics was given for meta-infective rescue. For the animals whose knee joint was movable, half an hour of passive 
joint exercise per day was applied after wound healing. The animals in all the groups were observed for 4 weeks after operation and were then sacrificed using intravenous air injection.

\section{Observation index}

Wound healing time in each group was determined. The healing standard was as follows: the skin wound satisfactorily healed; it was dry, and scabs formed without red swelling, exudation, or ischemic necrosis.

\section{Infection rates and gradients}

Infection rates and gradients were recorded. The evaluation standards were as follows: 1) slight infection: the skin displayed red swelling with tissue fluid exudation; 2) moderate infection: ischemic necrosis and rupture of the wound as well as purulent liquid exudation observed, but blood supply of the deep tissue normal; and 3) severe infection: skin wound necrosis, exudation of a large volume of purulent liquid, and ischemia-caused deactivation and degeneration of the deep tissue (knee joint scleron could be involved) observed.

\section{Knee joint function restoration}

Anterior and lateral X-rays of the affected tibia were performed at 0,2 and 4 weeks to observe fracture fixation and the healing of the broken ends of the fractured bone. The animals were sacrificed using the intravenous air injection method after 4 weeks of observation following the operation. Their knee joint and distal femur samples were taken, fixed, decalcified, and then stained with hematoxylin and eosin. The granulation tissue, fibrous tissue, cartilage callus, and hyperostosis between the broken ends of the fractured bone were observed under a light microscope and then pathologically graded on the basis of the following criteria: 1) grade 0: only granulation tissue or fibrous tissue between the broken ends; 2) grade I: preliminary healing with the main constituent being cartilage and a small amount of osseous calluses; 3) grade II: good healing with cartilage and osseous calluses in equal quantities; and 4) grade III: osseous healing with the primary constituent being osseous calluses and a small quantity of cartilage.

\section{Statistical analysis}

Data are reported as means \pm standard deviation. All data were analyzed using the SPSS13.0 software. Paired $t$-tests and one-way ANOVA were performed for the measured data of the limbs. Chi-square tests were used to compare infection rates, and nonparametric tests were used to compare the pathological grades of tissue healing. Differences of $\mathrm{P}<0.05$ were considered statistically significant and those of $\mathrm{P}<0.01$ as very significant.

\section{RESULTS}

\section{General conditions}

All animals ate and drank normally after operation, but these activities were somewhat limited due to knee joint fixation. After operation, all animals survived in group A, one 
died in group B, four died in group C, and one died in group D. All dead animals were replaced within 7 days after the operation.

\section{Wound healing and infection}

Animals with infection received debridement, regular change of dressing, and antibiotic treatment immediately. By the end of the observation period, all infected animals in group A healed, and three in group B, one in group C, and one in group D did not heal. Among the healed animals, the mean healing time of group A was $4.90 \pm 1.79$ days, whereas that of groups $\mathrm{B}, \mathrm{C}$ and $\mathrm{D}$ was $8.43 \pm 2.44,7.50 \pm 1.69$, and $7.33 \pm 1.00$ days, respectively. One-way ANOVA showed $F=6.577$ and $\mathrm{P}=0.002$. The healing time of each seawater immersion group was significantly longer than that of group A.

The infection rate of group A was $10 \%$, that of group B was $60 \%$, and that of groups $\mathrm{C}$ and $\mathrm{D}$ was $20 \% .2 \times \mathrm{K}$ table segmentation and paired comparisons showed that groups A, C, and $\mathrm{D}$ were annexable. The chi-square value obtained was 7.064 and $\mathrm{P}$ value was $0.014(\mathrm{P}<$ 0.05). According to these results, group B was more likely exposed to infection than any other group. The infection severity of each group is summarized in Table 1.

Table 1. Infections and healing in different groups.
\begin{tabular}{lccc} 
\\
Group & Slight infection $(\mathrm{N})$ & Moderate infection $(\mathrm{N})$ & Severe infection $(\mathrm{N})$ \\
\hline A & 1 & 0 & 0 \\
B & 1 & 2 & 3 \\
C & 0 & 2 & 0 \\
D & 1 & 1 & 0 \\
\hline
\end{tabular}

\section{Joint function rehabilitation}

At the end of the observation period, the knee joint on the affected side was generally larger than that on the healthy side. In groups B, C and D, the width of the affected knee joint was far larger than that on the healthy side as well as that on the same side in group $\mathrm{A}(\mathrm{P}<$ 0.01). The length of the affected knee joint was significantly shorter than that on the control side $(\mathrm{P}<0.01)$. The maximum streching angle of the affected knee joint was far smaller than that on the healthy side $(\mathrm{P}<0.01)$, as well as that on the same side in group $\mathrm{A}(\mathrm{P}<0.05)$. The minimum flexible angle of the affected knee joint was smaller than that on the healthy side (P $<0.05$ ). In addition, the streching angle of group D (the external fixation group) was smaller than that of groups $\mathrm{B}$ and $\mathrm{C}(\mathrm{P}<0.05)$. The minimum flexible angle of group $\mathrm{D}$ was smaller than that of groups $\mathrm{A}$ and $\mathrm{C}$ but did not show a significant difference compared with that of group B. Lower limb length and knee joint condition in each group are summarized in Table 2.

\section{Radiological observation}

Healing and infection at the broken ends were observed using consecutive anterior and lateral X-rays after fracture. At 4 weeks after operation, no noticeable fracture line or bone infection signs were observed in group A. In group B, three cases were observed with noticeable osseous infection signs, which were manifested by nonhealing and sparse and hazy sclerotin at the broken ends of the fractured bone. Bone resorption and osteonecrosis were ob- 
served at 4 weeks. In both groups $\mathrm{C}$ and $\mathrm{D}$, one case was observed with a noticeable fracture line but without apparent bone infection signs (Figure 1).

Table 2. Conditions of the lower limbs and knee joints in different groups 4 weeks after injury.

\begin{tabular}{|c|c|c|c|c|c|c|c|c|}
\hline \multirow[t]{2}{*}{ Group } & \multicolumn{2}{|c|}{ Width $(\mathrm{cm})$} & \multicolumn{2}{|c|}{ Length (cm) } & \multicolumn{2}{|c|}{ Extensible angle $\left({ }^{\circ}\right)$} & \multicolumn{2}{|c|}{ Flexible angle $\left({ }^{\circ}\right)$} \\
\hline & Healthy side & Affected side & Healthy side & Affected side & Healthy side & Affected side & Healthy side & Affected side \\
\hline A & $1.80 \pm 0.14$ & $1.92 \pm 0.20^{\mathbf{\Delta}}$ & $27.47 \pm 1.55$ & $26.60 \pm 1.60^{\wedge}$ & $169.80 \pm 4.13$ & $162.8 \pm 9.40^{\Delta \Lambda}$ & $21.2 \pm 2.10$ & $23.00 \pm 2.45$ \\
\hline B & $1.86 \pm 0.46$ & $2.62 \pm 0.58 \mathbf{\Delta} \Delta * *$ & $27.95 \pm 1.57$ & $25.65 \pm 2.85^{\boldsymbol{\Lambda}} \boldsymbol{\Delta}$ & $169.40 \pm 1.35$ & $147.10 \pm 21.10^{\mathbf{\Delta} * *}$ & $21.20 \pm 3.766$ & $30.10 \pm 7.38^{\mathbf{\Lambda}}$ \\
\hline $\mathrm{C}$ & $1.82 \pm 0.41$ & $2.56 \pm 0.49 \Delta \Delta * *$ & $28.25 \pm 1.31$ & $26.40 \pm 2.05^{\Delta \Lambda}$ & $170.4 \pm 2.50$ & $146.50 \pm 18.15^{\Delta \Delta} *$ & $20.20 \pm 1.93$ & $23.7 \pm 3.23^{\Delta \Delta \Delta}$ \\
\hline $\mathrm{D}$ & $2.12 \pm 0.33$ & $2.54 \pm 0.39^{\mathbf{\Delta} \Delta * *}$ & $27.9 \pm 1.17$ & $25.63 \pm 1.94^{\boldsymbol{\Lambda} \Delta}$ & $172.00 \pm 2.58$ & $129.30 \pm 15.81^{\mathbf{\Lambda} \Delta * * \Delta \text { 古 }}$ & $21.40 \pm 2.27$ & 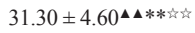 \\
\hline
\end{tabular}

Data are reported as means $\pm \mathrm{SD}$. $\boldsymbol{\Delta} \mathrm{P}<0.05$ and $\boldsymbol{\Lambda} \mathbf{\Lambda} \mathrm{P}<0.01$ vs the healthy side; $* \mathrm{P}<0.05$ and $* * \mathrm{P}<0.01$ vs group $\mathrm{A} ;{ }^{\Delta \mathrm{P}}<0.05$ and ${ }^{\Delta \Delta} \mathrm{P}<0.01$ vs group $\mathrm{B} ;{ }^{\wedge} \mathrm{P}<0.05$ and ${ }^{4}{ }^{\wedge} \mathrm{P}<0.01$ vs group $\mathrm{C}$.
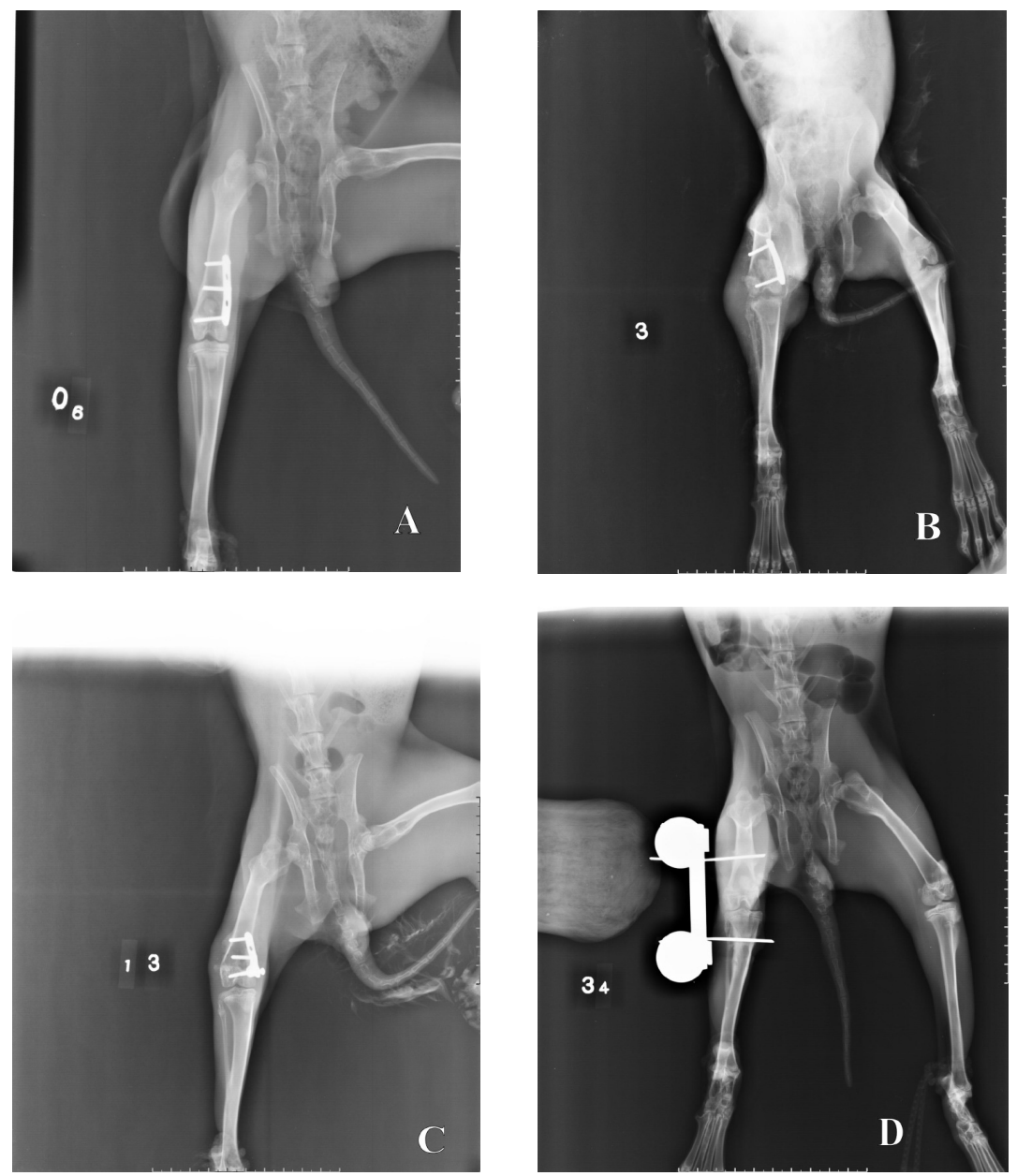

Figure 1. Radiological manifestations of the fractured knee joint 4 weeks after operation. A. Control group: the fractured knee joint has healed. B. Primary internal fixation group: infection, osseous resorption, and noticeable soft-tissue swelling occur. C. Delayed internal fixation group: the broken ends have healed. D. External fixation group: the fractured bone has satisfactorily healed with calluses growing along the Kirschner wire. 


\section{Pathological observation}

\section{General observation}

The seawater immersion groups showed more noticeable early local soft-tissue wound infection and much more exudate compared with the control group after operation. The infected animals showed local swelling and upheaval masses. Some animals were observed with drosslike exudates as well as bone exposure, destruction, and resorption at the broken ends, and some were observed with dry necrosis of local skin and patellar ligaments. In contrast, the uninfected animals did not exhibit noticeable abnormalities.

\section{Light microscopy}

According to the grading standards of fracture healing, eight animals demonstrated osseous healing with the other two showing good healing in group A, whereas no or poor healing was observed in any other group. In group B, three animals did not heal (Figure 2).
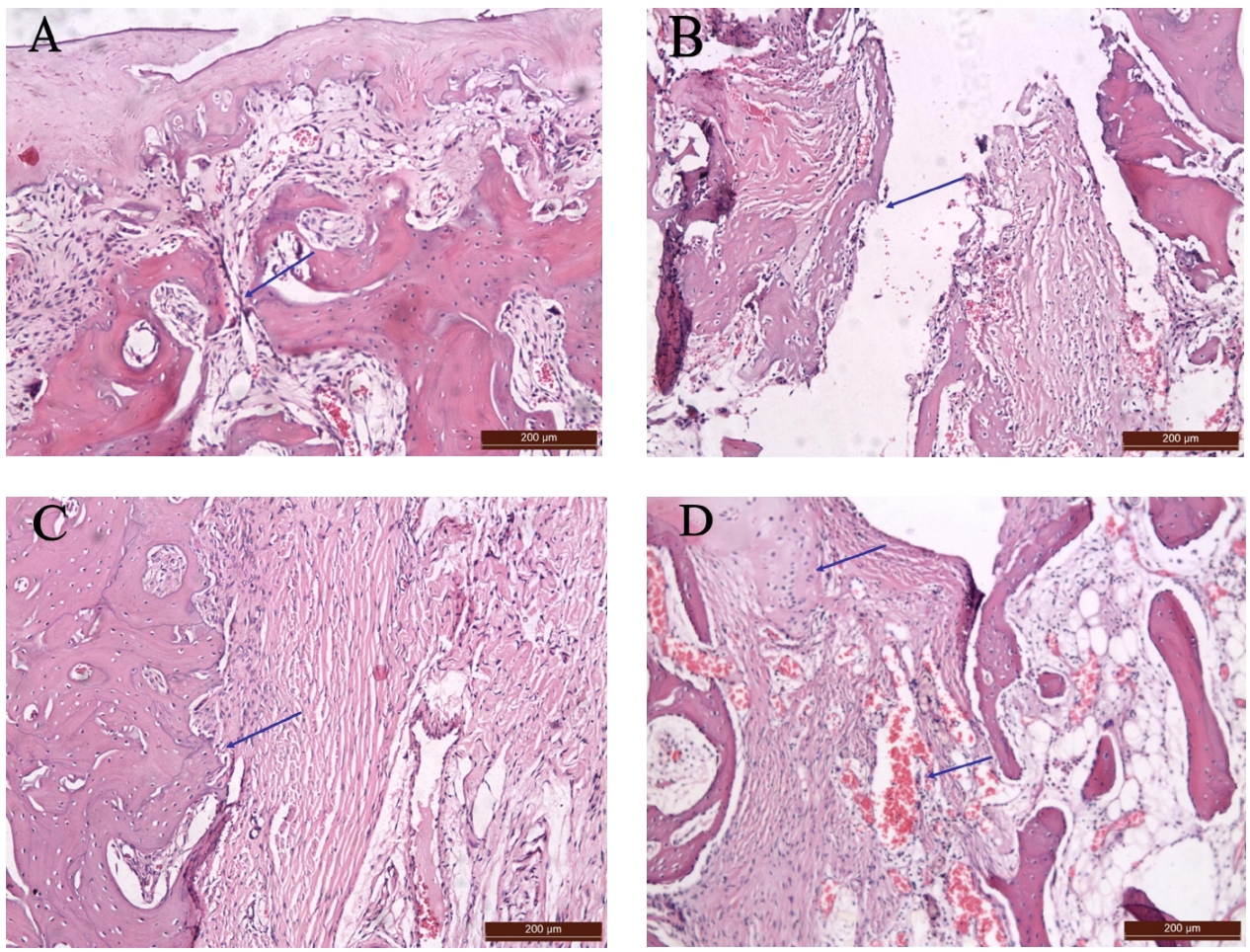

Figure 2. Histopathological manifestations of the fractured knee joint 4 weeks after operation. A. Control group: osseous healing is observed at the fracture site with osseous calluses as the primary constituents (arrows). B. Primary internal fixation group: unhealing is observed at the fracture site with fibrous tissues only growing at the bilateral broken ends. C. Delayed internal fixation group: good healing is observed at the broken ends with cartilages and fibrous tissues as the primary constituents. D. External fixation group: good fracture healing with osseous calluses, cartilage calluses, fibrous tissues, and a large number of vessels is observed. 
The tissue healing grades of the survivors in this group are summarized in Table 3. The differences in the healing levels between the groups were assessed using the nonparametric method in statistics, and the results showed that the healing rate of group B was noticeably lower than that of group $\mathrm{A}(\mathrm{P}<0.05)$, whereas no significant differences were observed between groups A, C, and D (Table 4). After fracture infection, infiltration of a large quantity of inflammatory cells into the marrow cavity and bone destruction and resorption were observed (Figure 3).

Table 3. Healing levels of the osseous tissue in different groups (N).
\begin{tabular}{llllr} 
Group & 0 & I & II & III \\
\hline A & 0 & 0 & 2 & 8 \\
B & 3 & 1 & 3 & 3 \\
C & 1 & 1 & 4 & 4 \\
D & 1 & 0 & 5 & 4 \\
\hline
\end{tabular}

\begin{tabular}{lcc}
\multicolumn{2}{c}{ Table 4. Paired comparison of osseous tissue healing between groups. } & \\
\hline Group & Chi-square value & P value \\
\hline A $v s$ B & 5.885 & 0.015 \\
A $v$ C & 3.646 & 0.056 \\
A $v$ D & 3.392 & 0.066 \\
B $v$ C & 0.762 & 0.383 \\
B $v s$ D & 1.088 & 0.297 \\
C $v s$ D & 0.042 & 0.837 \\
\hline
\end{tabular}
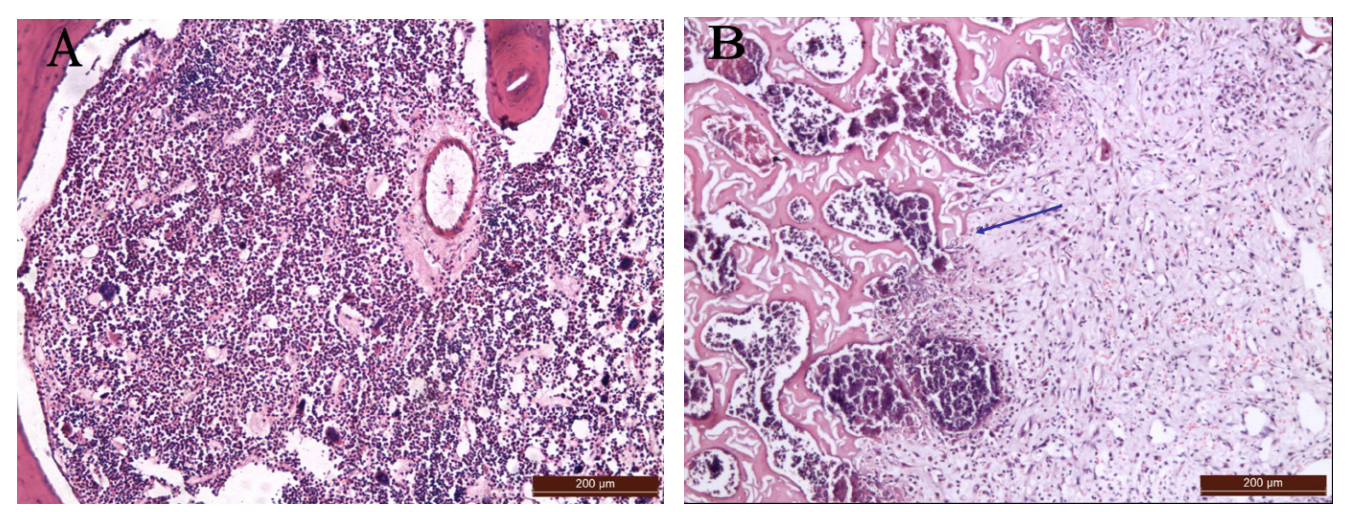

Figure 3. Histopathological manifestations of the fractured knee joint 4 weeks after infection (100X). A. Large quantity of inflammatory cells in the marrow cavity. B. Osseous destruction and resorption.

\section{DISCUSSION}

As sailing capacity and exploitation of marine resources develop in the world and as various countries continuously reinforce their navy, the incidence rates of sea trauma and seawater immersion-caused injury will definitely increase in the future. Particularly in coastal military clashes and regional battles in the future, blast injuries will greatly increase in modern 
sea battles. Accordingly, chip-caused open fractures will occur much more frequently and the number of soldiers with seawater immersion injury will greatly increase. Therefore, openbone fracture complicated by hypothermia and seawater immersion has become an urgent issue of logistic support in sea battles. In this study, we observed the effects of different treatment methods on wound infection, joint function rehabilitation, and fracture healing using rabbit seawater immersion-complicated knee joint fracture models. The curative effects were statistically analyzed and evaluated.

Seawater is characterized by high permeability, high sodium, high alkali, and hypothermia. It has an osmolarity 43 times that of human plasma, its sodium ion content is thrice that of human plasma, and its $\mathrm{pH}$ is alkaline. Generally, the temperature of seawater is below $20^{\circ} \mathrm{C}$, with the exception of tropical areas, which is much lower than normal human body temperature. Highly permeable, alkaline seawater can cause an increase in the local osmolarity of an open fracture, intracellular dehydration, and tissue space edema, directly stimulating histiocytes in the injured area to release inflammatory mediators such as IL-8, TNF and NO, reinforce lipid peroxidation, inhibit the activity of plasmalemmal Na-K-ATPase, inhibit clotting mechanisms, and aggravate the hemorrhage of small vessels in injured tissues. Meanwhile, these effects dilate vessels, which aggravates tissue edema and further reduces peripheral perfusion. After water seepage, peripheral perfusion improves, but reperfusion injury may occur, thereby leading to cardiovascular system injury (Lu et al., 2006). As heat loss in water is 3 -fold higher than in air at the same temperature, local wound soaking with seawater below human body temperature also exacerbates tissue energy metabolism disorders (Stoquart et al., 2008). This series of local and systemic pathophysiological reactions are detrimental to fracture healing, which is manifested by slow endochondral ossification, an increased undesirable rate, and weakened healed fractured bone intensity (Yang et al., 2005). In this study, osseous calluses were the primary form between the broken ends of the fractured bone in group A, whereas granulation, fibrous, and cartilaginous tissues were the primary forms in the seawater immersion groups. The healing effect in group B was noticeably worse than in group A. Although the healing level in groups $\mathrm{C}$ and $\mathrm{D}$ was lower than that in group $\mathrm{A}$, no significant differences were observed. Therefore, seawater immersion decreased the quality of fracture healing, which was even more apparent in primary steel plate internal fixation. These results indicate that seawater immersion has a serious impact on fracture healing, which is in complete accordance with those reported by other authors as well as what was expected by us.

Abundant bacteria exist in seawater, with about 100,000 bacteria per milliliter. Among these bacteria, Vibrio vulnificus is a particular species that tends to cause wound infection (Tikuisis, 1997). Furthermore, the composite physicochemical factors of seawater aggravate an open fracture and potentiate local inflammatory reactions, which promotes the proliferation of pathogenic bacteria (Reed et al., 1999). In this study, group B showed a significantly higher infection rate compared to group A, although both groups received the same primary internal fixation and the same postoperative treatment procedure. This result indicates that seawater immersion increases the infection rate after knee joint fracture and that seawater immersion has a significant influence on the development of infection after knee joint fracture (Ma et al., 2004, 2006; Hao et al., 2004, 2008). Furthermore, for knee joint fracture complicated by open fracture of the distal end of the femur, group B showed a significantly higher infection rate than did groups $\mathrm{C}$ and $\mathrm{D}$. Although both group $\mathrm{C}$ and group $\mathrm{D}$ showed a higher infection rate compared to the control group, the differences were not significant. Therefore, it is reasonably presumed that steel plate internal fixation + primary wound closure is not suitable for knee 
joint fracture and open fracture of the distal end of the femur complicated by seawater immersion, which tends to result in infection. The 3 days after seawater immersion-complicated open fracture is the fast bacterial proliferation period. During this period, the immunity of the organism is at a comparatively low level, which cannot inhibit the rapid growth of bacteria. Wound closure during this period will hinder wound drainage, and giving up the chance of delayed debridement and the natural self defense of the organism against bacteria will be bad for the prevention and cure of infection. Meanwhile, internal fixation damages tissue supply, which weakens the body's resistance to bacterial invasion, and the internally installed materials promote bacterial survival. These adverse effects further aggravate the development of infection. In contrast, external fracture fixation or delayed internal fixation after infection control does not aggravate soft-tissue wound and cause less local interference, thereby benefitting the observation and drainage of the wound. Furthermore, external fixation has the virtue that the para position and alignment of the fractured bone and the compression on it can be adjusted any time after operation on the basis of X-rays, which effectively reduces the infection rate after seawater immersion-complicated open-knee joint fracture.

Normally, external fixation of long bone fracture does not exceed the joint. Therefore, early joint functional training after external fixation does not greatly influence functional rehabilitation. External fixation is the treatment of choice for open fracture complicated by seawater immersion which does not need transarticular fixation (Xue et al., 2008). However, for open-knee joint and femoral distal-end fracture complicated by seawater immersion, transarticular external fixation is necessary to achieve a stable, reliable fixation effect, due to the specificity of the fractured site. Under such a condition, functional training cannot be performed during the external fixation period because of the fixed angle of the knee joint (Oetgen et al., 2010). This limitation may lead to joint functional deterioration and influence joint functional rehabilitation. Furthermore, external fixation has other drawbacks, such as pin hole infection (Rubinstein Jr. and DeHaan, 2010). In this study, the maximum streching angle of group D (the external fixation group) was smaller than that of group B (the primary internal fixation group) and group $\mathrm{C}$ (the delayed internal fixation group) $(\mathrm{P}<0.05)$, and its minimum flexible angle was smaller than that of group $\mathrm{A}$ (the control group) and group $\mathrm{C}$, but showed no significant difference compared with that of group B. These results indicate that long-term trans-knee joint external fixation is more likely to influence joint function rehabilitation compared with internal fixation. Delayed internal fixation means strict, thorough debridement and external fixation first for animals with fracture; this handling is then followed by internal fixation and joint function rehabilitation as soon as possible after infection is controlled (Checa et al., 2009; Smith et al., 2009). This treatment method benefits infection control (Oetgen et al., 2010), as well as early joint function training and rehabilitation.

In conclusion, for seawater immersion-complicated open-knee joint fracture, external fixation should be performed at an early stage after fracture for the sake of infection control and wound healing. After infection is successfully controlled, delayed internal fixation should be done. Meanwhile, early joint function training should be started, as it benefits infection rate reduction and knee joint function rehabilitation.

\section{REFERENCES}

Checa A, Eid H, Falasca G, Feinstein D, et al. (2009). Results of arthroscopic adhesiolysis and manipulation in the stiff knee secondary to septic arthritis and inflammatory arthritis. Rheumatol. Int. 29: 959-960. 
Gerding EC (2002). The 1982 south Atlantic conflict's aftermath. Int. Review Armed. Forces Med. Serv. 75: 84-94.

Hao XH, Ma C, Li YJ, Wang F, et al. (2004). The research about the wound infection of Vibrio damsela from some coastal area. Acad. J. PLA Postgraduate Med. School 25: 3-4.

Hao XH, Ma C, Fu KF, Zhang YF, et al. (2008). The research about the virulence and wound infection of the Shewanella putrefaciens from some coastal area. Acad. J. PLA Postgraduate Med. School 29: 487-488.

Lin JN and Ruan DK (2004). Histopathology and expression of VEGF in callus during the healing process of open fracture under seawater immersion. Chin. J. Orthopaedic Trauma 6: 885-888.

Lu SM, Liu JC, Shi CH, Li P, et al. (2006). Effects of seawater immersion on the functions of mitochondria of myocardium and hepatocyte in hemorrhagic shock rats. Chin. J. Traumatol. 9: 38-42.

Ma C, Han SQ, Hao XH, Jiang XB, et al. (2004). Acterium spectrum of Southeast China Sea area and wound infection ability of dominant bacteria. Acad. J. Second Mil. Med. Univ. 26: 1365-1367.

Ma C, Hao XH, Wang F, Li YJ, et al. (2006). Wound Infectivity by Vibrio parahaemolyticus derived from seacoast. Chin. J. Nosocomiol. 16: 986-989.

Oetgen ME, Walick KS, Tulchin K, Karol LA, et al. (2010). Functional results after surgical treatment for congenital knee dislocation. J. Pediatr. Orthop. 30: 216-223.

Reed KC, Crowell MC, Castro MD and Sloan ML (1999). Skin and soft-tissue infections after injury in the ocean: culture methods and antibiotic therapy for marine bacteria. Mil. Med. 164: 198-201.

Rubinstein RA Jr and DeHaan A (2010). The incidence and results of manipulation after primary total knee arthroplasty. Knee 17: 29-32.

Smith AM (1995). Medical implications of war at sea. Navy Med. 86: 13-19.

Smith EL, Banerjee SB and Bono JV (2009). Supracondylar femur fracture after knee manipulation: a report of 3 cases. Orthopedics 32: 18.

Stoquart GG, Detrembleur C, Palumbo S, Deltombe T, et al. (2008). Effect of botulinum toxin injection in the rectus femoris on stiff-knee gait in people with stroke: a prospective observational study. Arch. Phys. Med. Rehabil. 89: 56-61.

Tikuisis P (1997). Prediction of survival time at sea based on observed body cooling rates. Aviat. Space Environ. Med. 68: 441-448.

van der Krogt MM, Bregman DJ, Wisse M, Doorenbosch CA, et al. (2010). How crouch gait can dynamically induce stiffknee gait. Ann. Biomed. Eng. 38: 1593-1606.

von Bertele M (2007). Military medicine in the Falklands war. J. R. Army Med. Corps 153 (Suppl 1): 3-5.

Wang JH, Zhao JZ and He YH (2007). A new treatment strategy for severe arthrofibrosis of the knee. Surgical technique. J. Bone Joint Surg. Am. 89 (Suppl 2): 93-102.

Xue Q, Lin JN, Xu C, Li C, et al. (2008). The experiment study of the different surgical management for the open fracture with seawater immersion. J. Pract. Orthopaedics 14: 595-599.

Yang WZ, Ruan DK and Lin JN (2005). The early management of femoral open fracture after seawater immersion. Chin. J. Orthopaedics Trauma 7: 250-253. 